\title{
ASSESSMENT OF SURGICAL MANAGEMENT OF FEMALE BREAST CANCER PATIENTS AFTER NEOADJUVANT SYSTEMIC THERAPY FOR INVASIVE DUCTAL VERSUS INVASIVE LOBULAR CARCINOMA (T3 STAGE)
}

\author{
By
}

\section{El-Said Ahmed Mahmoud Douma, Saied Hosny Bendary, Ahmed Yosry El-Agamawi*, Amr Mahmoud Zayed**, Nader Mohamed Abd El-Hamid}

Departments of General Surgery, Clinical Oncology \& Nuclear Medicine* and Radiodiagnosis**, Faculty of Medicine, Al-Azhar University

E-mail: elsaid.a.douma@gmail.com

\begin{abstract}
Background: In the treatment of locally advanced breast cancer, neoadjuvant chemotherapy approach has several objectives, including downsizing of irresectable tumor into operable disease.

ILC is known to be less responsive to NAC. The reported proportions of ILC patients with a pathologic complete response (pCR) range from 1 to $3 \%$ compared with 9 to $15 \%$ for IDC patients

Objectives: To assess surgical decision after using neoadjuvant systemic therapy for locally advanced breast cancer patients with invasive ductal carcinoma (IDC) versus whom with invasive lobular carcinoma (ILC). To determine the impact of neoadjuvant chemotherapy (NAC) on different pathological types of locally advanced breast cancer cases.

Patients and Methods: This retrospective study included 50 patients in the period from Jun 2018 to Jun 2019 who were diagnosed as invasive ductal and invasive lobular Carcinoma classified into two equal groups. Each group had received neoadjuvant systemic therapy, at Department of Clinical Oncology and Nuclear Medicine, while surgical treatment, in form of modified radical mastectomy (MRM) or breast conserving surgery (BCS), was done between June 2019 and Mar 2020, at the Surgical Oncology Department in Al-Azhar university hospitals.
\end{abstract}

Results: In our study, we observed a reduction in T stage after NAC in 6 cases (24\%) of ILC patients compared to clinical down staging in 20 cases (80\%) of IDC group.

Conclusion: ILC patients were less responsive to neoadjuvant chemotherapy compared with IDC patients. BCS is less frequently achieved after NAC in patients with lobular histology compared with ductal histology.

Keywords: Locally advanced breast cancer, neoadjuvant chemotherapy, surgical management, invasive duct carcinoma, invasive lobular carcinoma.

\section{INTRODUCTION}

Worldwide breast cancer is the most common invasive cancer in women. In 2012, it comprised $25.2 \%$ of cancers diagnosed in women, (Kwon and Seungjun, 2016).
Neoadjuvant chemotherapy (NAC) is considered the standard treatment for the management of locally advanced breast cancer and is increasingly being used for women with earlier stage disease (Aragon-Ching et al., 2018). The 
neoadjuvant chemotherapy approach has several objectives, including downsizing of irresectable locally advanced breast cancer into operable disease to increase the possibility of conservative breast surgery (CBS) (Henderson et al., 2017).

Furthermore, it allows in vivo monitoring of the tumor's chemosensitivity. And also gives the opportunity for downstaging of disease in the axilla, obviating the need for axillary treatment in some patients (Chehade et al., 2016).

ILC is known to be less responsive to NAC. The reported proportions of ILC patients with a pathologic complete response (pCR) range from 1 to $3 \%$ compared with 9 to $15 \%$ for IDC patients (Loibl et al., 2014).

Endocrine therapy alone (aromatase inhibitor or tamoxifen) may be considered for patients with hormone-receptor positive disease as a preoperative therapy, (Huober et al., 2012).

Invasive lobular carcinoma (ILC) is the second most common subtype of invasive breast cancer (BC), accounting for approximately $5-15 \%$ of all invasive tumors (Michaut et al., 2016).

ILC offers an exclusive clinical, radiological and pathological appearance compared to invasive ductal carcinoma (IDC). For example, ILC is always an estrogen-receptor positive tumor with a high frequency of multicentricity and laterality. It is more commonly associated with older age, larger diameter and welldifferentiated morphology (Veys et al., 2015).

Furthermore, in a small study including patients with ILC, NAC did not appear to increase the likelihood of breast conservation. Also, when treated with NAC, patients with ILC have been more likely to have positive surgical margins than patients with IDC (Marmor et al., 2017).

This study aimed to compare the impact of neoadjuvant systemic therapy on the patients with invasive ductal versus invasive lobular breast cancer in form of difference in response and surgical management.

\section{PATIENTS AND METHODS}

This prospective study included fifty female patients, ranging from 20-60 years old, classified into two equal groups with proven histopathology of locally advanced invasive lobular or invasive ductal carcinoma of the breast. All patients had completed her neoadjuvant chemotherapy with Anthracyclin-based regimen, with or without hormonal therapy according to receptors status, at the Department of Clinical Oncology and Nuclear Medicine, while surgical treatment, in form of modified radical mastectomy (MRM) or breast conserving surgery (BCS), was done between June 2019 and Mar 2020, at the Surgical Oncology Department in AlAzhar university hospitals.

Patients were excluded if they had any of the following criteria. Patients with early stage of breast cancer, metastatic breast cancer, not in the period from June 2019 to Mar 2020 and medically unfit for surgery.

After NAC, each patient was subjected to comprehensive medical history and careful clinical examination for assessment of clinical response to NAC and the patient's ability to perform 
surgery. Laboratory and radiological investigations for preparation for surgery, excluding metastasis and assessment of breast lesion response to neo-adjuvant treatment. All patients had been subjected to surgical treatment in the form of modified radical mastectomy or conservative breast surgery according to the results of NAC.

The patients were informed of the study and signed a consent term of their participation, after explanation of possible complications, ethical and legal implications. They underwent modified Radical Mastectomy or conservative breast surgery.

Postoperative clinical follow-up was done at three months intervals, and included local examination of chest wall, both breasts and axilla. Tumor marker (CA 15-3), mammograms, and ultrasonography were done according to our protocol.

\section{Statistical Analysis:}

The collected data was revised, coded, tabulated and introduced to a PC using Statistical package for Social Science (IBM Corp. Released 2011. IBM SPSS Statistics for Windows, Version 20.0.
Armonk, NY: IBM Corp). Data was presented and suitable analysis was done according to the type of data obtained for each parameter.

- Description of quantitative variables as mean, SD and range.

- Description of qualitative variables as number and percentage.

- Chi-square test was used to compare qualitative variables.

- Two sample t-tests were used to compare quantitative variables between independent groups in parametric data.

- Paired t-test was used to assess the statistical significance of the difference between two means measured twice for the same study group.

- McNemar test was used assess the statistical significance of the difference between a qualitative variable measured twice for the same study group.

- P- value was considered Signihceut when $\mathrm{P}$-value $<0.05$.

\section{RESULTS}

According to the patient's age and chronic diseases at time of presentation, (estimated median age was $50.52 \pm 6.22$ years for IDC and $51.48 \pm 4.04$ for ILC) There is no significant difference between the studied groups. While there is significant deference between the two groups as regard BMI, the patients of ILC is more likely to be over weigh and obese than IDC patients (Table 1). 
Table (1): Demographic data of all patients

\begin{tabular}{|c|c|c|c|c|}
\hline \multirow{2}{*}{ Parameters } & Groups & IDC group & ILC group & \multirow{2}{*}{ P-value } \\
\cline { 3 - 5 } Age (year) & Mean \pm SD & $50.52 \pm 6.22$ & $51.48 \pm 4.04$ & \multirow{2}{*}{$<0.521$} \\
\cline { 2 - 4 } & Range & $38-60$ & $43-58$ & \\
\hline \multirow{2}{*}{ BMI } & Mean \pm SD & $26.65 \pm 2.30$ & $28.02 \pm 2.46$ & \multirow{2}{*}{$<0.049$} \\
\cline { 2 - 4 } & Range & $24.07-33.06$ & $23.94-32.32$ & \\
\hline \multirow{2}{*}{ HTN } & No & $10(40.0 \%)$ & $13(52.0 \%)$ & \multirow{2}{*}{$<0.395$} \\
\cline { 2 - 4 } & Yes & $15(60.0 \%)$ & $12(48.0 \%)$ & \\
\hline \multirow{2}{*}{ DM } & No & $14(56.0 \%)$ & $18(72.0 \%)$ & \multirow{2}{*}{$<0.239$} \\
\cline { 2 - 4 } & Yes & $11(44.0 \%)$ & $7(28.0 \%)$ & \\
\hline \multirow{2}{*}{ IHD } & No & $19(76.0 \%)$ & $18(72.0 \%)$ & \multirow{2}{*}{$<0.747$} \\
\cline { 2 - 4 } & Yes & $6(24.0 \%)$ & $7(28.0 \%)$ & \\
\hline
\end{tabular}

All patients conducted to our study selected in T3 stage (LABC) tumor, size more than $5 \mathrm{~cm}$, and all patients have positive axillary $\mathrm{LN}$ (N1) by clinical examination and ultrasonographic investigation. No skin manifestation or metastatic lesion (Table 2).

Table (2): Tumor stage of both groups at time of presentation before NAC

\begin{tabular}{|c|c|c|c|c|c|}
\hline \multirow{2}{*}{ Parameters Groups } & \multicolumn{2}{|c|}{ IDC group } & \multicolumn{2}{c|}{ ILC group } \\
\cline { 2 - 6 } \multicolumn{2}{|c|}{} & No. & \% & No. & \% \\
\hline \multirow{2}{*}{$\mathrm{T}$} & $\mathrm{T} 3$ & 25 & $100.0 \%$ & 25 & $100.0 \%$ \\
\cline { 2 - 6 } & $\mathrm{T} 2$ & 0 & $0.0 \%$ & 0 & $0.0 \%$ \\
\hline \multirow{2}{*}{$\mathrm{N}$} & $\mathrm{N} 0$ & 0 & $0.0 \%$ & 0 & $0.0 \%$ \\
\cline { 2 - 6 } & $\mathrm{N} 1$ & 25 & $100.0 \%$ & 25 & $100.0 \%$ \\
\hline $\mathrm{M}$ & $\mathrm{M} 0$ & 25 & $100.0 \%$ & 25 & $100.0 \%$ \\
\hline
\end{tabular}

All pre-therapeutic core needle biopsies that were confirmed to show invasive breast carcinoma were automatically subjected for automated immunostaining assessment for estrogen receptor $(\mathrm{ER})$, progesterone receptor $(\mathrm{PR})$ and HER-2/neu. Patients with ILC were more likely to have positive ER in $(80 \%)$ and positive PR in $(76 \%)$ of cases, compared to patients with IDC home have positive ER in (40\%) and positive PR in $(36 \%)$ of cases which highly significant. Also, patients with ILC were more likely to have HER2 negative tumor in $(76 \%)$ of cases rather than HER2 positive tumors (24\%), while patients with IDC showed more HER2 positive tumor $(64 \%)$ and less HER2 negative tumor (36\%), which statistically significance ( $\mathrm{p}$ value $<0.005$ ) (Table 3). 
Table (3): Comparison between the groups regarding the status of hormonal receptors and Her-2/neu

\begin{tabular}{|c|c|c|c|c|c|c|}
\hline \multirow{2}{*}{ Parameters } & Groups & \multicolumn{2}{|c|}{ IDC group } & \multicolumn{2}{|c|}{ ILC group } & \multirow{2}{*}{ P-value } \\
\cline { 3 - 7 } & & No. & $\mathbf{\%}$ & No. & \% & \\
\hline \multirow{2}{*}{ ER } & Negative & 15 & $60.0 \%$ & 5 & $20.0 \%$ & \multirow{2}{*}{$<0.004$} \\
\cline { 2 - 6 } & Positive & 10 & $40.0 \%$ & 20 & $80.0 \%$ & \\
\hline \multirow{2}{*}{ PR } & Negative & 16 & $64.0 \%$ & 6 & $24.0 \%$ & \multirow{2}{*}{$<0.005$} \\
\cline { 2 - 6 } & Positive & 9 & $36.0 \%$ & 19 & $76.0 \%$ & \\
\hline \multirow{2}{*}{ Her2neu } & Negative & 9 & $36.0 \%$ & 19 & $76.0 \%$ & \multirow{2}{*}{$<0.005$} \\
\cline { 2 - 6 } & Positive & 16 & $64.0 \%$ & 6 & $24.0 \%$ & \\
\hline
\end{tabular}

After NAC, patients of group A showed remarkable response by clinical examination and ultrasonographic investigation in (80\%) which became $\mathrm{T} 2$ instead of T3 before NAC. The tumors in group B experienced clinical downstaging only in (24\%). This result was statistically significant. As regards to axillary response to NAC, only $(56 \%)$ cases of group A (IDC) became N0, compared to (40\%) from cases of group B (ILC), which was statistically nonsignificant (Table 4).

Table (4): Comparison of two groups regarding clinical response to NAC

\begin{tabular}{|c|c|c|c|c|c|c|}
\hline \multirow{2}{*}{ Parameters } & \multirow{2}{*}{ Groups } & \multicolumn{2}{|c|}{ IDC group } & \multicolumn{2}{c|}{ ILC group } & \multirow{2}{*}{ P-value } \\
\cline { 3 - 6 } & & No. & \% & No. & \% & \\
\hline \multirow{2}{*}{$\mathrm{T}$} & $\mathrm{T} 3$ & 5 & $20.0 \%$ & 19 & $76.0 \%$ & \multirow{2}{*}{$<0.001$} \\
\cline { 2 - 6 } & $\mathrm{T} 2$ & 20 & $80.0 \%$ & 6 & $24.0 \%$ & \\
\hline \multirow{2}{*}{$\mathrm{N}$} & $\mathrm{N} 0$ & 14 & $56.0 \%$ & 10 & $40.0 \%$ & \multirow{2}{*}{$<0.258$} \\
\cline { 2 - 6 } & $\mathrm{N} 1$ & 11 & $44.0 \%$ & 15 & $60.0 \%$ & \\
\hline $\mathrm{M}$ & $\mathrm{M} 0$ & 25 & $100.0 \%$ & 25 & $100.0 \%$ & NA \\
\hline
\end{tabular}

Among group A, (IDC) downstaging achieved in $(80 \%)$ of cases and conservative surgery achieved in 17 cases $(68 \%)$. In the group B, (ILC) only, 6 cases
(24\%) experienced downstaging and conservative surgery performed in these 6 cases, which was statistically significant (Table 5).

Table (5): Comparison between the two groups regarding downstaging and type of surgery performed

\begin{tabular}{|c|c|c|c|c|c|c|}
\hline \multirow{2}{*}{ Groups } & \multicolumn{2}{|c|}{ IDC group } & \multicolumn{2}{|c|}{ ILC group } & \multirow{2}{*}{ P-value } \\
\cline { 3 - 7 } \multicolumn{2}{|c|}{ Parameters } & No. & $\mathbf{\%}$ & No. & \% & \\
\hline \multirow{2}{*}{ Down Staging } & No & 5 & $20.0 \%$ & 19 & $76.0 \%$ & \multirow{2}{*}{$<0.001$} \\
\cline { 2 - 6 } & Yes & 20 & $80.0 \%$ & 6 & $24.0 \%$ & \\
\hline \multirow{2}{*}{ Type of Surgery } & MRM & 8 & $32.0 \%$ & 19 & $76.0 \%$ & \multirow{2}{*}{$<0.002$} \\
\cline { 2 - 6 } & CBS & 17 & $68.0 \%$ & 6 & $24.0 \%$ & \\
\hline Local Recurrence & No recurrence & 25 & $100.0 \%$ & 25 & $100.0 \%$ & NA \\
\hline
\end{tabular}

In the ILC patients, MRM was the primary surgical intervention done in 19 cases $(76 \%)$ while CBS done in 6 cases
(24\%). In the IDC patients, the BCS was the main surgical procedure 17 cases $(68 \%)$ and MRM done for 8 cases (32\%). 


\section{DISCUSSION}

The Neoadjuvant chemotherapy (NAC) is the first line of treatment for patients with locally advanced breast cancer. The objectives, including downsizing of irresectable locally advanced breast cancer into operable disease. Furthermore, it allows in vivo monitoring of the tumor's chemo sensitivity and also gives the opportunity for down staging of disease in the axilla, obviating the need for axillary treatment in some patients. This study was conducted to determine the impact of neoadjuvant chemotherapy (NAC) on different pathological types of locally advanced breast cancer cases. We compared the effects of NAC on the surgical decision for two similar groups of patients with locally advanced invasive lobular carcinoma (ILC) and locally advanced invasive ductal carcinoma (IDC).

In our study, we observed a reduction in $\mathrm{T}$ stage after NAC in (24\%) of ILC patients compared to clinical down staging in $(80 \%)$ of IDC group. Our results were near to previous study of Nagao et al, whom observed reduction in $\mathrm{T}$ stage after NAC in $31.8 \%$ of the patients with ILC and $75 \%$ of the patients with IDC. They found that down staging was more frequently observed in the patients who presented with larger size and hormone receptor-negative tumors in both histologic subtypes (Nagao et al., 2012).

There was no impact of breast cancer histology on the use of breast conservation and the risk of positive resection margins and interventions is well established. Since the introduction of NAC for locally advanced tumors, BCS can be achieved more. However, the surgical benefits after NAC for patients with locally advanced breast cancer of lobular histology compared with ductal histology remain unclear (Truin et al., 2016).

Our study showed a remarkable low percentage of patients undergoing BCS after NAC for ILC group (24 \%) compared to $68 \%$ BCS for IDC group. These BCS rates were lower than the data in literature as the study of (Cain et al. 2017), which pooled nine randomized trials that calculated a BCS rate was (59.1 $\%)$ for ILC patients and $(71.1 \%)$ for IDC patients after NAC (Salati et al., 2018).

In another meta-analysis of Petrelli and Barni (2013) on the response after NAC for locally advanced breast cancer, and concluded that the $\mathrm{BCS}$ rates were $35.4 \%$ for ILC and $54.8 \%$ for IDC. This was nearly similar to our results.

The differences in percentage between BCS results after NAC for different histology is due to that patients with ILC present with significantly larger tumors at the time of diagnosis, and more often show multifocal or multicentric disease. The diffuse infiltrative growth pattern of ILC poses a difficulty in determining the extent of the tumor. As a result of these characteristics, higher rates of positive surgical resection margins are observed in the primary surgical procedure in ILC compared with IDC. This results in higher rates of re-resection and completion mastectomy for patients with lobular histology (Truin et al., 2016).

The definition of a pathological complete response (pCR) was necrosis and the disappearance of all invasive cells in post-operative specimen and this observed only in cases with infiltrating 
ductal carcinoma (Gebreamlak et al., 2013). In our study, there was no cases show pCR. Patients with IDC are more likely to experience a pCR than patients with ILC, especially when their tumors are ER-, PR- negative and HER2-neu positive (Barquet-Muñoz et al., 2015). The reported proportions of ILC patients with a pathologic complete response range from 1 to $3 \%$ compared with 9 to $15 \%$ for IDC patients (Lobbes et al., 2013).

\section{CONCLUSION}

BCS were less frequently achieved after NAC in patients with lobular histology compared with ductal histology.

Conflicts of Interest: The authors declare that there were not any conflicts of interest regarding the publication of this paper.

Acknowledgment: The authors would like to thank all staff members, residents, nurses and ancillary staff of the Surgical Oncology Department, Al Azhar University Hospitals and El Matarya Teching Hospital for their precious help. Prof, Yasser Ali from Al Azhar University Hospitals, Egypt, for his great help preparing the manuscript, Finally, we would like to thank our kind patients for their helpful participance.

\section{REFERENCES}

1. Aragon-Ching JB, Werntz RP, Zietman AL, Werntz RP and Steinberg GD (2018): Multidisciplinary Management of MuscleInvasive Bladder Cancer Current Challenges and Future Directions. American Society of Clinical Oncology Educational Book, 38(12): 307-318.

2. Barquet-Muñoz, SA, Villarreal-Colin SP, Herrera-Montalvo LA, Soto-Reyes E, Pérez-Plasencia C, Coronel-Martínez J and De León DC (2015): Metaplastic breast cancer: a comparison between the most common histologies with poor immunohistochemistry factors. BMC cancer, 15(1): 75-84.

3. Chehade, HEH, Headon H, Kasem $A$ and Mokbel K (2016): Refining the performance of sentinel lymph node biopsy postneoadjuvant chemotherapy in patients with pathologically proven pre-treatment nodepositive breast cancer: an update for clinical practice. Anticancer research, 36(4): 14611471.

4. Gebreamlak E, MK Tse $G$ and Niu $Y$ (2013): Progress in evaluation of pathologic response to neoadjuvant chemotherapy of breast cancer. Anti-Cancer Agents in Medicinal Chemistry (Formerly Current Medicinal Chemistry-Anti-Cancer Agents), 13(2): 222-226.

5. Henderson JR, Kandola S, Hignett SP, Teasdale RL, Topps AR, Pennick $M$ and Kirwan CC (2017): Infection Prophylaxis for Breast Implant Surgery: Could We Do Better? Eplasty, 17.

6. Huober J, Fasching PA, Barsoum M, Petruzelka L, Wallwiener D, Thomssen C and Kubista E (2012): Higher efficacy of letrozole in combination with trastuzumab compared to letrozole monotherapy as firstline treatment in patients with HER2positive, hormone-receptor-positive metastatic breast cancer-results of the eLEcTRA trial. The Breast, 21(1): 27-33.

7. Kwon S and Seungjun L (2016): Recent advances in microwave imaging for breast cancer detection. International Journal of Biomedical Imaging, 8(13): 1-26.

8. Lobbes MB I, Prevos R, Smidt M, TjanHeijnen VCG, Van Goethem M, Schipper R and Wildberger, J. E. (2013): The role of magnetic resonance imaging in assessing residual disease and pathologic complete response in breast cancer patients receiving neoadjuvant chemotherapy: a systematic review. Insights into imaging, 4(2): 163-175.

9. Loibl S, Volz C, Mau C, Blohmer JU, Costa S D, Eidtmann H, Kümmel S (2014): Response and prognosis after neoadjuvant chemotherapy in 1,051 patients with 


\section{EL-SAID AHMED MAHMOUD DOUMA et al.,}

infiltrating lobular breast carcinoma. Breast cancer research and treatment, 144(1): 153162.

10. Marmor S, Hui JYC, Huang JL, Kizy S, Beckwith H, Blaes AH and Tuttle TM (2017): Relative effectiveness of adjuvant chemotherapy for invasive lobular compared with invasive ductal carcinoma of the breast. Cancer, 123(16): 3015-3021.

11. Michaut M, Chin SF, Majewski I, Severson TM, Bismeijer T, De Koning L and Tarrant F (2016): Integration of genomic, transcriptomic and proteomic data identifies two biologically distinct subtypes of invasive lobular breast cancer. Scientific reports, 6(43): 1849-18517.

12. Nagao $\mathbf{T}$, Kinoshita $\mathbf{T}$, Hojo $\mathbf{T}$, Tsuda $\mathbf{H}$ and Tamura $K$ (2012): The differences in the histological types of breast cancer and the response to neoadjuvant chemotherapy: the relationship between the outcome and the clinicopathological characteristics. The Breast, 21(3): 289-295.

13. Petrelli F and Barni S (2013): Response to neoadjuvant chemotherapy in ductal compared to lobular carcinoma of the breast: a metaanalysis of published trials including
1764 lobular breast cancer. Breast Cancer Res Treat., 14(142): 227-235.

14. Salati A, Akbari, ME, Nafissi N, Noorian S, Mahdavi SR, Mirzaei HR and Shahani M (2018): Comparison of outcome between invasive lobular carcinoma (ILC) and invasive ductal carcinoma (IDC) patients treating with breast conserving surgery (BCS) and radical dose of intraoperative electron radiotherapy (IOERT). International Journal of Cancer Management, 11(11): 145-162.

15. Truin W, Vugts G, Roumen RM, Maaskant-Braat AGJ and Nieuwenhuijzen GAP (2016): Differences in response and surgical management with neoadjuvant chemotherapy in invasive lobular versus ductal breast cancer. Annals of surgical oncology, 23(1): 51-57.

16. Veys I, Pop CF, Barbieux R, Moreau M, Noterman D, De Neubourg $F$ and Bourgeois $P$ (2018): ICG fluorescence imaging as a new tool for optimization of pathological evaluation in breast cancer tumors after neoadjuvant chemotherapy. PloS one, 13(5): e0197857. 


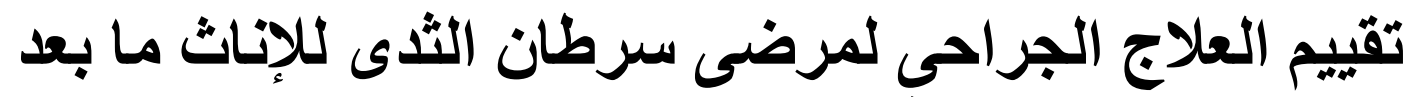

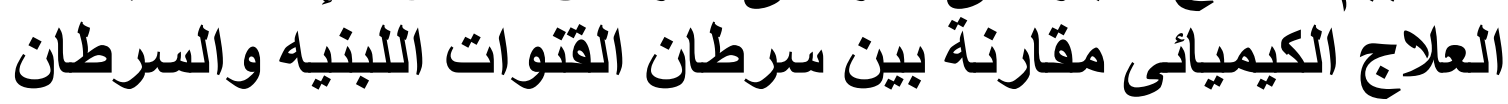

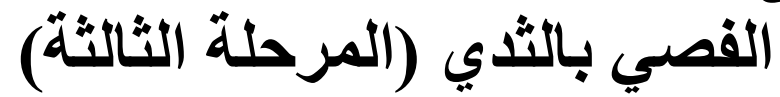

السعيد احمد محمود دومة، سعيد حسنى بندارى، احمد يسرى العجماوى*، عمرو محمود زايد**، نادر محمد عبد الحميل

أقسام الجراحة العامة، الطب النووى* والأشعة التشخيصية**، كلية الطب، جامعة الأزهر

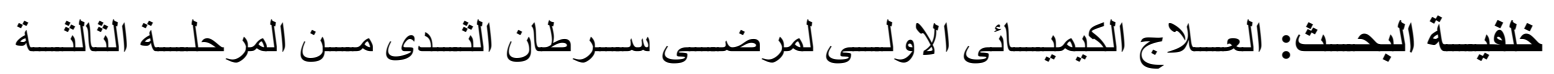

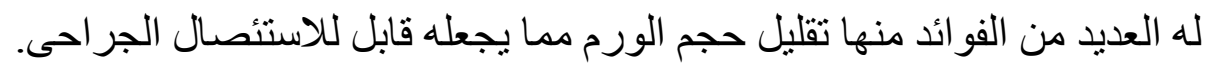

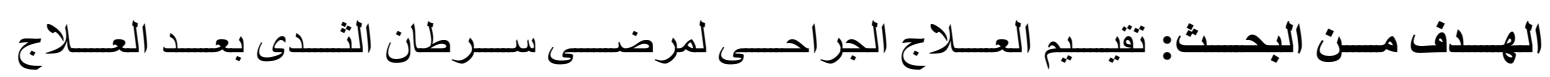
الكيميائى مقارنة بين سرطان الفصى للثنى وسرطان الغدد اللبنية.

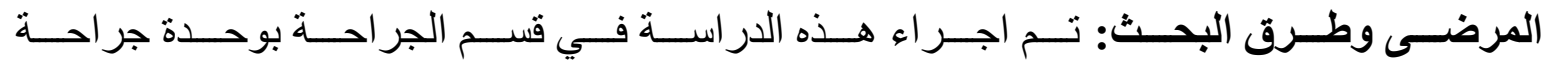

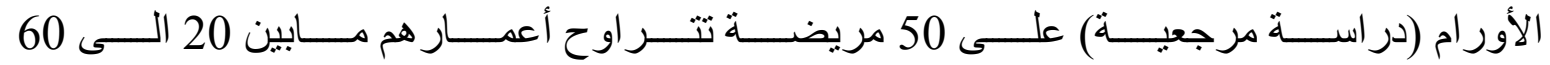

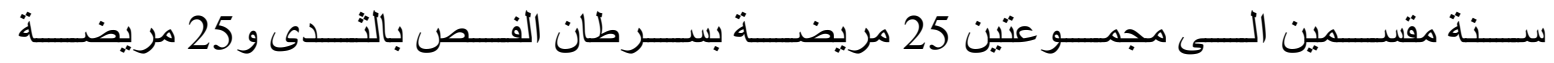

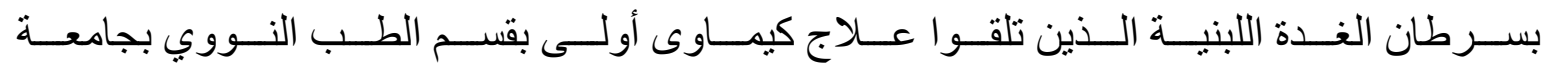

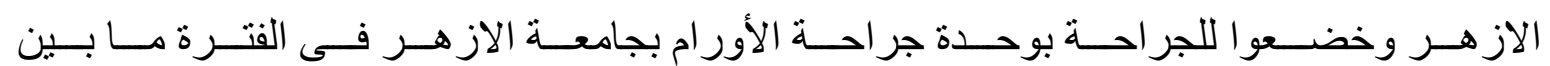
شهر يونيو 2019 إلى شهر مارس وخطر 2020.

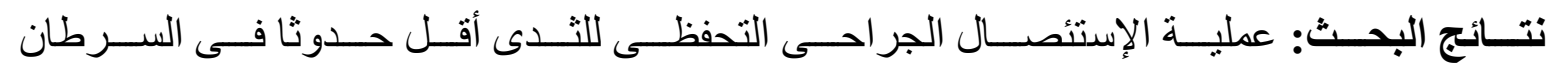

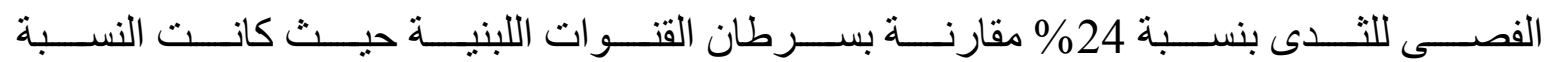

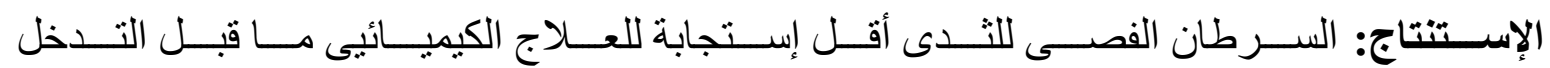

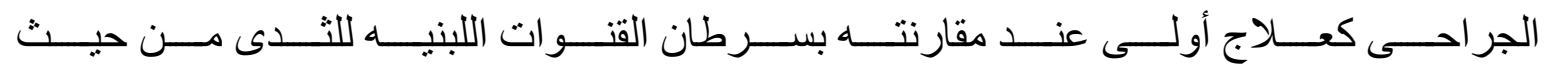
الإستجابه الإكلينكيه، و الباتولوجيه التامه، والإستئصال الجر احى التحفظى للثذى. 